\title{
Vulnerabilidad a la pobreza y juventud Entre la desprotección y el adultocentrismo
}

\author{
Vulnerability to Poverty and Youth: Lack of Protection and Adultcentrism
}

\author{
Ana Heatley Tejada*
}

Resumen: Este artículo revisa los factores de riesgo y fragilidad que colocan a los jóvenes en una posición de mayor vulnerabilidad a la pobreza, en comparación con los adultos. Se revisan factores estructurales, como el diseño de la protección social institucionalizada y del mercado laboral, y factores relacionales, como las transiciones, la discriminación y el adultocentrismo, para trazar un panorama amplio de las situaciones que pueden tener efectos adversos en las condiciones de vida de este grupo de población. Este análisis podría contribuir a dar mayor coherencia a la política social dirigida a los jóvenes, que se ha centrado en explotar su potencial para promover el crecimiento económico dejando de lado el bienestar presente y futuro de las personas que hoy son jóvenes.

Palabras clave: jóvenes, vulnerabilidad, riesgo, desigualdad, adultocentrismo.

Abstract: This article analyses risk factors and fragility conditions that expose Mexican youth to an increased vulnerability to poverty, compared to adults. Structural factors — such as the institutional design of social protection and the labour market — and relational factors — such as discrimination and adultcentrism - are examined to gain a wider and more comprehensive perspective on the situations that might have adverse effects in the living conditions of this population group. This study could contribute to improve the coherence of public policy for the youth, which has focused on exploiting youth's potential for economic growth over present and future well-being of the people who are currently young.

Keywords: youth, vulnerability, risk, inequality, adultcentrism.

*Ana Heatley Tejada al momento de escribir este artículo era investigadora del Departamento de Estudios sobre Desigualdad Social y Poblaciones Vulnerables del Consejo Nacional de Evaluación de la Política y Desarrollo Social, Insurgentes Sur 810, col. Del Valle, 03100, cDMX. Actualmente es investigadora en Oxfam México. Correo-e: ana.heatley@gmail.com. ORCID ID 0000-0002-9547-2179.

Articulo recibido el 12 de diciembre de 2019 y aceptado para su publicación el 19 de marzo de 2021.

http://dx.doi.org/10.29265/gypp.v31i1.1015 


\section{INTRODUCCIÓN}

Tos jóvenes son un tema emergente en los estudios de vulnerabilidad a la pobreza en México (Conapred, 2018a; Coneval, 2018c) y conforman un grupo de población relativamente inexplorado. Esta situación es comprensible si se considera que la prevalencia de pobreza en la juventud es de 41 por ciento en $2018,{ }^{1}$ prácticamente la misma que el promedio nacional (42\%). Generar información y política social que los atienda también es una preocupación relativamente nueva y la atención de la política dedicada a la juventud se centra en otros factores como el aprovechamiento de su mano de obra y la necesidad de desarrollar su capital humano para tal efecto. ${ }^{2}$ Por otro lado, en la literatura especializada, los estudios de otros grupos como los niños y la población indígena son mucho más abundantes y anteriores a los de jóvenes (Coneval, 2014b, 2014a); la prevalencia de pobreza es notoriamente mayor en estas poblaciones $(51 \mathrm{y} 75 \%$, respectivamente).

No obstante, existen algunos diagnósticos de instituciones federales como el Consejo Nacional de Evaluación de la Política de Desarrollo Social (Coneval) y el Consejo Nacional para Prevenir la Discriminación (Conapred) que, pese a presentar un panorama relativamente inconexo, identifican a la pobreza como un problema importante para la juventud (Conapred, 2018b, 2019; Coneval, 2018c), junto con una serie de problemáticas que sí afectan a los jóvenes de manera característica: desempleo y empleo precario; desconexión entre educación y empleo, y ausencia de capacitación; programas y servicios de salud que no están diseñados para sus necesidades (como la falta de medicina preventiva y de atención a la salud sexual y reproductiva, etc.); la violencia; el embarazo adolescente; la discriminación (Conapred, 2018a, 2018b; Coneval, 2018a, 2018b). Todos estos factores tienen efectos adversos en el bienestar de los jóvenes, pero no todos se traducen en un riesgo mayor a encontrarse en condiciones de pobreza.

${ }^{1}$ Población entre 15 y 29 años. Cálculos propios con datos del Coneval (2018d). Es importante tener en cuenta que la prevalencia de pobreza en la juventud puede ser aparentemente igual al promedio nacional porque la metodología de medición no es sensible a sus circunstancias como individuos. Por ejemplo, un joven que se queda sin empleo durante la pandemia (o su negocio se va a la quiebra) y se ve obligado a volver a casa de sus padres sin ingresos propios, podría considerarse no pobre si el hogar en su conjunto tiene recursos suficientes para que los ingresos per cápita de cada integrante estén por encima de la línea de pobreza, aunque el joven en cuestión tenga deudas y ningún ingreso. Sin embargo, la posible subestimación de la pobreza juvenil y las limitaciones de la metodología oficial rebasan los alcances de este estudio, pero es importante tener en mente que las cifras podrían estar subestimadas por las características de la metodología oficial.

${ }^{2}$ Muestra de ello es que el Instituto Mexicano de la Juventud fue creado en 1999 con el objetivo de atender a la población joven no por encontrarse en condiciones de vulnerabilidad sino por la importancia estratégica de este grupo de población para el desarrollo del país (DOF, 1999). 
Por lo tanto, este artículo se propone analizar las fuentes de fragilidad y riesgo de los jóvenes mexicanos respecto a la pobreza con el objetivo de identificar los factores sistémicos y estructurales que generan la vulnerabilidad en este grupo de población. El enfoque de pobreza no basta; un análisis de las circunstancias actuales de la juventud bajo un enfoque más amplio que la prevalencia de pobreza pone al descubierto los riesgos que enfrentan y que no necesariamente quedan reflejados en las cifras y diagnósticos actuales. Dicho análisis es necesario para dar estructura a la política social dirigida a este grupo de población que ha estado notablemente limitada a algunos factores educativos, económicos y laborales, usualmente más ventajosos para sus empleadores que para ellos. Y también es necesario para resolver la inconsistencia entre identificar a la pobreza como un riesgo que los afecta y el hecho de que las cifras oficiales no muestren una prevalencia mayor al promedio nacional.

\section{MÉTODO}

\section{Marco conceptual}

Para examinar las condiciones de riesgo de los jóvenes mexicanos, que no son visibles en términos de prevalencia de pobreza, este estudio recurre a los enfoques de vulnerabilidad y de desigualdad social. De esta manera es posible observar, primero, si los jóvenes se encuentran en riesgo y, segundo, si lo están de manera particular.

La vulnerabilidad a la pobreza se entiende como la propensión al daño o a sufrir cambios negativos respecto a las condiciones de vida que caracterizan a la pobreza. Las causas de la vulnerabilidad pueden ser las características de los individuos o de su relación con otras personas e instituciones que resultan en mayor exposición al riesgo o en mayor fragilidad (Busso, 2001; Feito, 2007; Moreno Crossley, 2008). La fragilidad es una situación donde una persona tiene menos recursos para enfrentar las condiciones adversas pese a, o independientemente de, que esté expuesta a dichas condiciones en la misma medida que cualquier otra persona. Algunas fuentes de fragilidad características de los jóvenes son la falta de protección social y la poca posibilidad de ahorro y acumulación de recursos valiosos (dinero y características que resulten atractivas en el mercado laboral.) En cambio, la mayor exposición se refiere a una mayor frecuencia o intensidad al experimentar condiciones adversas, independientemente de los recursos con los que se cuente. Algunas de las fuentes de exposición a riesgos más importantes en el caso de los jóvenes son la discriminación directa y estructural, la desprotección a las transiciones en el curso de vida y las políticas laborales de la actualidad. 
Por su parte, el enfoque de desigualdad examina las diferencias en las circunstancias de los grupos sociales que no se pueden atribuir a variaciones aleatorias o que no están justificadas de manera objetiva. En este estudio se analizan los riesgos que afectan a los jóvenes de manera particular en comparación con los adultos (que constituyen el grupo hegemónico) dado el orden social institucionalizado actualmente. Es importante tener en cuenta que vulnerabilidad y desigualdad no son lo mismo. La vulnerabilidad no necesariamente es desigual, pero en este caso me interesa explorar las condiciones de fragilidad de los jóvenes versus las de los adultos.

El concepto de adultocentrismo (Duarte Quapper, 2012; Unicef, 2013) se utiliza aquí como guía para analizar la desigualdad estructural. Adultocentrismo es organizar la sociedad a partir del mundo - necesidades, perspectivas, experiencias, control político - de las personas consideradas adultas (Duarte Quapper, 2012; Unicef, 2013) y afecta a todos los otros grupos etarios. Aunque no sólo los jóvenes padecen el adultocentrismo, probablemente tienen la menor protección, pues la expectativa social es que comiencen "desde abajo" y se mantengan en esa posición durante algún tiempo antes de mejorar sus condiciones de vida, laborales o sociales. Esto puede invisibilizar la situación de vulnerabilidad y desigualdad en la juventud y se suma a una particularidad de este grupo: la juventud se quita y las desventajas estructurales que viven los jóvenes se diluyen o se confunden con procesos temporales.

Dado que la juventud es una etapa social que trasciende a los meros cambios biológicos que ocurren en ella, no hay criterios unívocos para definirla (Dávila, 2004; Téllez Infantes, 2013). Diferentes instituciones e investigadores establecen rangos de edad variables de acuerdo con los objetivos que se plantean y en México comúnmente se ha utilizado el criterio de 12 a 29 años para definir a la población joven (Coneval, 2018c; DOF, 1999). La juventud se caracteriza por las transiciones a la adultez, tales como el ingreso al mercado laboral, la emancipación o unión y tener hijos. El orden y el momento en el que las personas atraviesan por estas transiciones es muy variable, pero los estudios han mostrado que en México las principales transiciones ocurren entre los 15 y los 29 años (Nájera Catalán, 2016). Por ello, la definición operativa de juventud para este estudio se estableció en ese rango de edad.

El documento consta de tres secciones. En la primera se analizan los factores de fragilidad y en la segunda, los factores de riesgo. La tercera aborda las implicaciones para la política pública de los resultados presentados en las secciones previas. 


\section{Objetivos}

El presente estudio tiene por objetivo responder a las siguientes preguntas: ¿cuáles son las fuentes de vulnerabilidad a la pobreza para la juventud mexicana? ¿Enfrentan el mismo nivel de riesgo que los adultos? Para responder a dichas preguntas se plantean dos hipótesis: $a$ ) los jóvenes tienen una mayor exposición y fragilidad al riesgo de pobreza debido a que enfrentan una serie de eventos adversos - transiciones desprotegidas y limitado acceso a recursos - porque no reciben protección institucional y enfrentan discriminación directa y estructural; b) dicha exposición es característica de la juventud, en comparación con los adultos.

El estudio se realizó en México utilizando los datos de las encuestas nacionales, principalmente la Encuesta Nacional de Ingresos y Gastos de los Hogares (ENIGH), ${ }^{3}$ la Encuesta Nacional de Ocupación y Empleo (ENOE), la Encuesta Nacional de la Dinámica Demográfica (Enadid) y la Encuesta Nacional sobre Discriminación (Enadis).

\section{FRAGILIDAD: DESPROTECCIÓN SOCIAL Y FALTA DE ACCESO A RECURSOS}

Como ya se dijo, la fragilidad es una de las facetas de la vulnerabilidad y se caracteriza por una menor resistencia producto de la falta de recursos de diversa índole para hacer frente o recuperarse ante condiciones adversas, como un shock económico. Los principales recursos con los que se puede evitar la pobreza son los ingresos y las formas institucionalizadas de protección social que están diseñados para que las personas puedan hacer frente a situaciones como un gasto catastrófico en salud o la pérdida de ingresos cuando no se puede trabajar.

La evidencia de la vulnerabilidad de los jóvenes a la pobreza se observaría entonces en un acceso limitado a recursos institucionales — seguridad social—y monetarios - ingresos - y no sólo en una mayor prevalencia de pobreza. Además, las limitaciones en el acceso a los recursos serían desiguales respecto a otros grupos etarios. Dichas condiciones pueden ser resultado del diseño institucional o de diferentes formas de exclusión social.

\section{Seguridad social: pensiones y salud}

Los sistemas de seguridad social estatales en México se organizan alrededor del trabajador asalariado con prestaciones. Esto tiene dos tipos de limitantes: primero,

\footnotetext{
${ }^{3}$ Se optó por analizar los datos de 2014 dado que la información disponible para 2016 y 2018 se basa en una estimación del ingreso (no en observaciones) a partir de un modelo estadístico para la comparabilidad (véase Coneval, 2016).
} 
coloca a todas las personas que no sean trabajadoras asalariadas con prestaciones en una posición de desprotección o de dependencia (que, a su vez, representa un riesgo) y, segundo, no considera las necesidades de todas aquellas personas, trabajadoras o no, que no sigan el esquema de empleo protegido, como los trabajadores informales, temporales, subcontratados o no regulados.

Asociar los sistemas de seguridad social al empleo formal es un problema para toda la población. El problema se agudiza entre los jóvenes, que tienen mayor desempleo (Coneval, 2018b), mayor rotación (Cunningham, 2009), mayor empleo informal (Coneval, 2018b; INEGI, 2014) y menor acceso a fondos para el retiro o peores condiciones en los esquemas de jubilación respecto a los adultos. Los jóvenes están en un contexto de precarización del mercado laboral (De Oliveira, 2006) que el Estado no ha alcanzado a contener y son una generación expuesta a la subcontratación y a la falta de regulación en muchos empleos emergentes, como las aplicaciones. Así, la vinculación de la seguridad social con el trabajo formal asalariado es, al mismo tiempo, un factor de fragilidad y de desigualdad para los jóvenes, que se encuentran en desventaja en el mercado laboral.

El mismo diseño de la seguridad social vinculado al empleo formal repercute seriamente en el acceso a la salud y en las condiciones materiales de vida cuando se alcanza la edad de jubilación o existe una incapacidad para trabajar. El análisis de los datos desde la perspectiva de la vulnerabilidad y la desigualdad pone de manifiesto la fragilidad y desventaja a las que se enfrenta la juventud en el ámbito de la seguridad social, particularmente los fondos para el retiro y los servicios de salud.

\section{Resultados}

En México, los jóvenes tienen menor acceso a la seguridad social que cualquier otro grupo de edad: 68 por ciento de las personas entre 15 y 29 ańos no tuvo acceso - medido con el indicador de carencia de Coneval-, contra 59 por ciento de las personas entre 30 y 59, y 27 por ciento en mayores de 60 años (INEGI, 2014). Pese a que, con datos de la misma encuesta, 51 por ciento de los jóvenes trabajó el mes anterior al levantamiento, 74 por ciento de ellos no tuvo la prestación de Sistema de Ahorro para el Retiro (SAR) o Afore en ese empleo.

Además de tener menor acceso a la seguridad social, la situación se vuelve más crítica para quienes ingresaron al mercado de trabajo después de la privatización del sistema de pensiones que introdujo el financiamiento individual por medio de administradoras de fondos para el retito (Afore). En 2014, todos los menores de 24 años van a financiar su propio retiro y todos contribuirán, además, a financiar el retiro de generaciones anteriores por medio del pago de impuestos. Pero 
5 por ciento está desempleado — contra menos de 3 por ciento entre los adultosy sólo 18 por ciento de los que trabajaron tuvo la prestación de Afore en su empleo. Es decir, la generación de jóvenes que entró al mercado de trabajo después de 2007 está expuesta a una triple carga: primero, a un nivel de desempleo que duplica al de los adultos; segundo, a los niveles más altos de empleo sin fondos para el retiro de cualquier grupo de edad; tercero, a autofinanciar su retiro pero seguir contribuyendo a financiar el retiro de las generaciones previas mediante el pago de impuestos.

Suponiendo que la privatización del sistema de pensiones fuera una necesidad insoslayable y que se adoptó la solución más eficiente posible, ${ }^{4}$ no hay evidencia de que se hayan tomado medidas compensatorias para evitar que los efectos negativos se concentraran injustamente en los jóvenes. El Estado se ha hecho cargo del déficit en los ingresos de los adultos mayores por medio de programas de transferencias. Sin embargo, la política pública dirigida a mejorar el empleo y los ingresos en el caso de los jóvenes es casi inexistente. La puesta en marcha del programa Jóvenes Construyendo el Futuro es una primera iniciativa a gran escala, aunque está dirigida a la capacitación para el empleo y no al empleo mismo, y los montos de la beca son relativamente bajos (STPS, s.f.). Otro ejemplo es el programa de Primer Empleo en México, pero no está dirigido específicamente a los jóvenes. Además, los mayores subsidios se otorgan a los empleos con salarios menores, de manera que los empleadores obtienen el máximo beneficio contratando a jóvenes para los empleos con peores salarios. El programa no incluye incentivos para que los nuevos empleados accedan a los puestos de alta calificación.

En cuanto al acceso a la salud, el panorama es similar. En primera instancia, los jóvenes tienen menor acceso a los servicios de salud (24 por ciento no tiene acceso) que los adultos (17\%), pero esto también se asocia con el acceso al empleo formal, pues el porcentaje de jóvenes sin acceso a servicios de salud baja a 2 por ciento ( 1 por ciento en el caso de los adultos) entre aquellos que tienen Afore como prestación laboral (INEGI, 2014), es decir, un empleo formal.

En segundo lugar, el diseńo de los servicios de salud desfavorece a los jóvenes, pues se concentra en los problemas que típicamente afectan a otros grupos de población y desatiende las necesidades características de la juventud (Coneval, 2018c). La medicina preventiva, la salud sexual y reproductiva y el bienestar psicológico, que son muy relevantes en esta etapa de la vida, ocupan un lugar secundario en los servicios de salud estatales. En cambio, la atención a enferme-

\footnotetext{
${ }^{4}$ Todo esto es un supuesto duramente criticado (oIT, 2015; Ramírez, 2019).
} 
dades y padecimientos que usualmente se manifiestan en la edad adulta, en la vejez o en la primera infancia reciben mucho más recursos y atención. Se ha reportado que la cobertura efectiva del Seguro Popular es 89 por ciento para la salud materno-infantil, pero para las enfermedades no transmisibles y lesiones apenas alcanza 32 por ciento (Medina-Mora et al., 2009).

Además, de acuerdo con las estadísticas de mortalidad de 2016 del INEGI, ${ }^{5}$ los jóvenes tienen una tasa de suicidio mayor que cualquier otro grupo de edad y, sin embargo, la atención psicológica no es accesible. Se ha encontrado que, en México, el inicio de los trastornos mentales ocurre durante la juventud en una gran variedad de casos (Medina-Mora et al., 2003) y, sin embargo, la atención puede llegar de 4 a 20 años después, dependiendo del trastorno (Medina-Mora et al., 2009).

\section{Recursos monetarios: salarios, ahorro y deuda}

La falta de acceso a recursos monetarios para hacer frente de manera individual a las condiciones adversas debido a la falta de protección del Estado son una segunda fuente de fragilidad. Además de que hay mayor desempleo juvenil que adulto, entre los ocupados existe una desigualdad sistemática en los salarios de los diferentes grupos de edad. Esta desigualdad se considera justificada cuando se debe a diferencias en puestos de mayor responsabilidad o jerarquía, a la experiencia o la antigüedad. Es decir, una parte considerable de la desigualdad salarial se justifica consuetudinariamente con argumentos meritocráticos respecto a la mayor experiencia laboral que, en general, tienen los adultos respecto a los jóvenes.

En primera instancia, cabe reflexionar sobre si mayor experiencia es justificación suficiente para que exista una desigualdad salarial, particularmente cuando es imposible que los jóvenes que ingresan al mercado de trabajo cuenten con ella, y considerando que los retornos de la educación — que es la ventaja competitiva de las nuevas generaciones - son cada vez menores (Szekely y Flores, 2018). Pero incluso si la experiencia fuera un criterio razonable para asignar salarios distintos, no existe información suficiente para distinguir entre antigüedad —entendida como tiempo en un mismo empleo-, experiencia — entendida como práctica adquirida en una actividad específica, aunque no sea en la misma institución-y edad laboral —entendida como tiempo que una persona ha pasado dentro del mercado de trabajo sin importar si adquirió habilidades en la resolución de problemas o si adquirió antigüedad. En consecuencia, no hay manera de comprobar que la diferencia en salarios se explique por diferencias en experiencia, y que esta

\footnotetext{
${ }^{5}$ Disponible en: https://www.inegi.org.mx/temas/mortalidad/\#Tabulados
} 
a su vez refleje la productividad del trabajador. Es decir, no es posible saber si la desigualdad salarial por razones de edad responde a una diferencia objetiva o a una forma de discriminación.

Aunado a los ingresos laborales, las personas pueden hacer frente a los riesgos mediante el ahorro o la deuda. Pero el hecho de que exista mayor informalidad, desempleo, rotación y salarios bajos entre los jóvenes, además de limitar el acceso a la seguridad social y a los ingresos laborales, impide la generación de ahorros. Así, los jóvenes se encontrarán en una situación de desventaja social y estructural generalizada que, si bien podría superarse en la adultez con el paso del tiempo, deja secuelas importantes en su trayectoria laboral y económica. La OIT ha estimado que tener un primer empleo formal y con buenas condiciones de trabajo mejora considerablemente las condiciones laborales en los empleos posteriores (OIT, 2015).

La falta de ahorro y las deudas son resultado tanto de circunstancias generales - factores macroeconómicos - como específicas que impactan a los jóvenes en mayor medida —el diseño de los esquemas de retiro, por ejemplo—, y aunque tiene consecuencias importantes para toda la población, afecta a los jóvenes de manera particular. Por ejemplo, obstaculiza la emancipación. Salir de casa de los padres, ya sea en pareja o individualmente, implica muchos gastos iniciales. En estas condiciones, las compras a crédito se vuelven una alternativa, aunque a un costo elevado. El conjunto de estas limitantes podría considerarse una penalización a la independencia que afecta característicamente a los jóvenes y pone en evidencia que, a circunstancias similares de ingresos, los jóvenes pueden resultar más afectados que los adultos.

\section{Resultados}

Los jóvenes ganan menos que los adultos en todas las categorías de empleo, diferencia que suele estar justificada por factores como la experiencia. El reto es discernir si se trata de una situación justa o equitativa dado que las fuentes de información no permiten distinguir experiencia, antigüedad, edad laboral y productividad para comparar la situación de los jóvenes respecto a los adultos. Esta carencia se solventó con dos estrategias. La primera fue considerar sólo los empleos donde la experiencia no es relevante en términos de las recompensas del mercado. Tal es el caso de los trabajadores en actividades elementales y de apoyo. Los jóvenes están desproporcionadamente concentrados en este tipo de trabajos, que además tienen el salario promedio más bajo del mercado (20.6 pesos por hora). Es decir, uno de cada tres jóvenes (30\%) está empleado en la categoría de traba- 
GRÁFICA 1. Distribución de los grupos de edad por tipo de trabajo

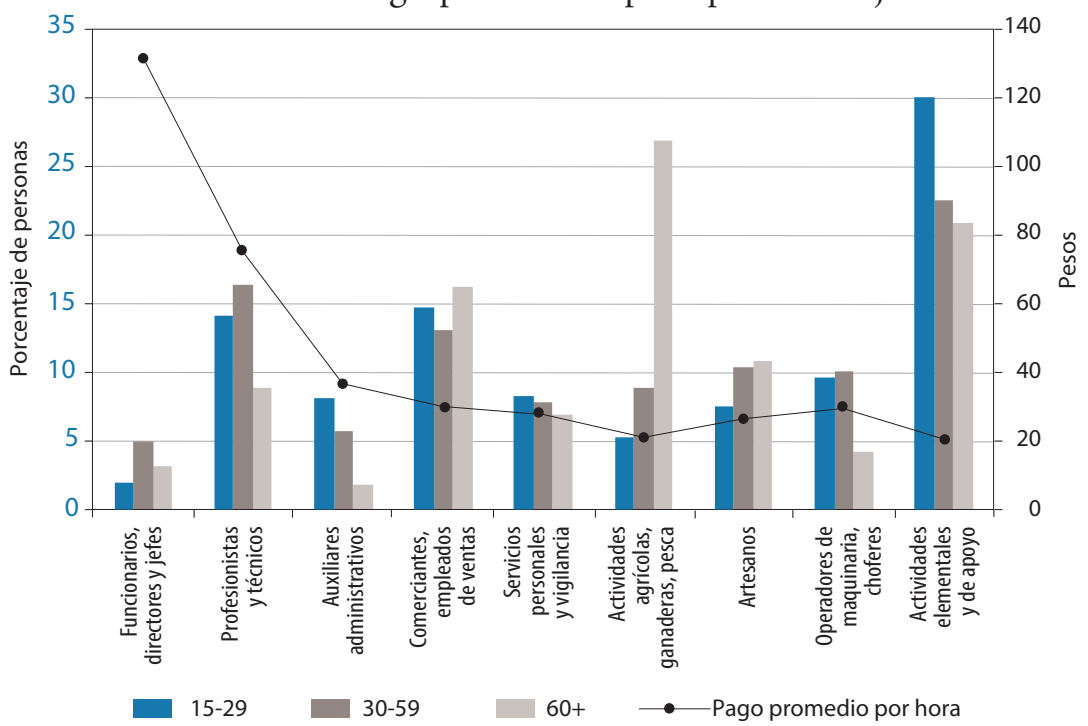

Fuente: Elaboración propia con base en datos de la ENIGH (INEGI, 2014).

jo con menor salario, porcentaje que se reduce a 23 por ciento entre los adultos y a 21 por ciento entre los mayores (gráfica 1 ).

Además de la concentración desproporcionada, dentro de esta misma categoría, los jóvenes tienen salarios más bajos que los adultos: 15 pesos por hora, en promedio, para los primeros y 20 pesos para los segundos. La brecha no se cierra con la educación, pues un joven con educación media superior gana, en promedio, casi lo mismo que un adulto sin educación (gráfica 2). Cabe mencionar que este cálculo no considera a los puestos de supervisión, que podrían recibir salarios más altos por tener mayor jerarquía.

Si en esta categoría de empleo — excluyendo los puestos de supervisión-, la experiencia no es relevante o no es recompensada por el mercado, y si los jóvenes tienen la educación y la fuerza suficiente como para ser igual o más productivos que los adultos, ¿por qué ganan menos?

La segunda estrategia fue observar el patrón de diferencias en salarios entre los jóvenes, los adultos y los mayores. ${ }^{6} \mathrm{Si}$ los adultos ganan más porque tienen

\footnotetext{
${ }^{6}$ Personas que tienen 60 años o más pero que siguen trabajando.
} 
GRÁFICA 2. Pago por hora en actividades elementales y de apoyo por grupos de edad y nivel de escolaridad

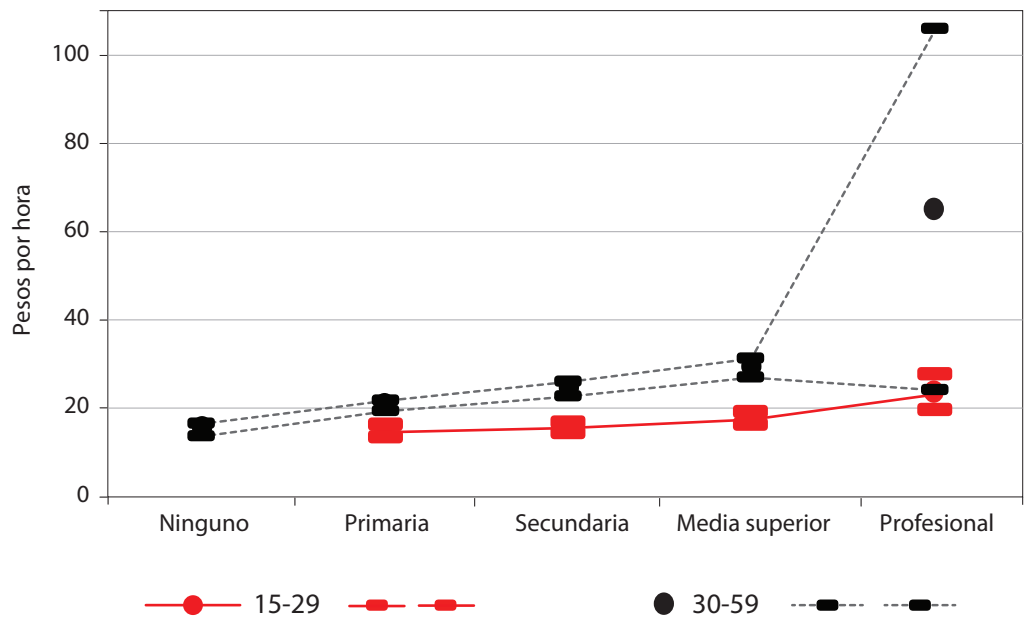

Fuente: Elaboración propia con base en datos de la ENIGH (INEGI, 2014).

más experiencia en general —es decir, que la experiencia se asocia a la edad—, se esperaría que los mayores tengan salarios más altos que los adultos, dado que, usualmente, tienen la mayor experiencia. Pero este patrón no se observa en general (gráfica 3), lo cual resta fuerza a la justificación de la desigualdad salarial por la experiencia que se gana con la edad.

Se podría argumentar que los mayores no tienen los ingresos laborales más altos que los adultos porque la productividad decae con la edad. Esto implicaría, primero, aceptar que la experiencia y la productividad no necesariamente van juntas. Por otro lado, las categorías donde los mayores ganan más que los adultos son categorías donde la productividad es un factor altamente valorado: funcionarios, directivos y jefes; profesionistas y técnicos; y operadores de maquinaria industrial, ensambladores, choferes y conductores de transporte. Para que la justificación de la experiencia se sostenga, se tendría que aceptar que el mercado recompensa a los mayores en estos ámbitos con salarios más altos aunque sean menos productivos. Aquí los criterios dejan de ser justos para los jóvenes que simplemente no pueden competir con los otros grupos etarios.

De nuevo, en el nivel más simple de análisis, los datos necesarios para distinguir los efectos de la experiencia, la productividad, la edad laboral o los 
GRÁFICA 3. Pago por hora por tipo de empleo y grupos de edad, 2014

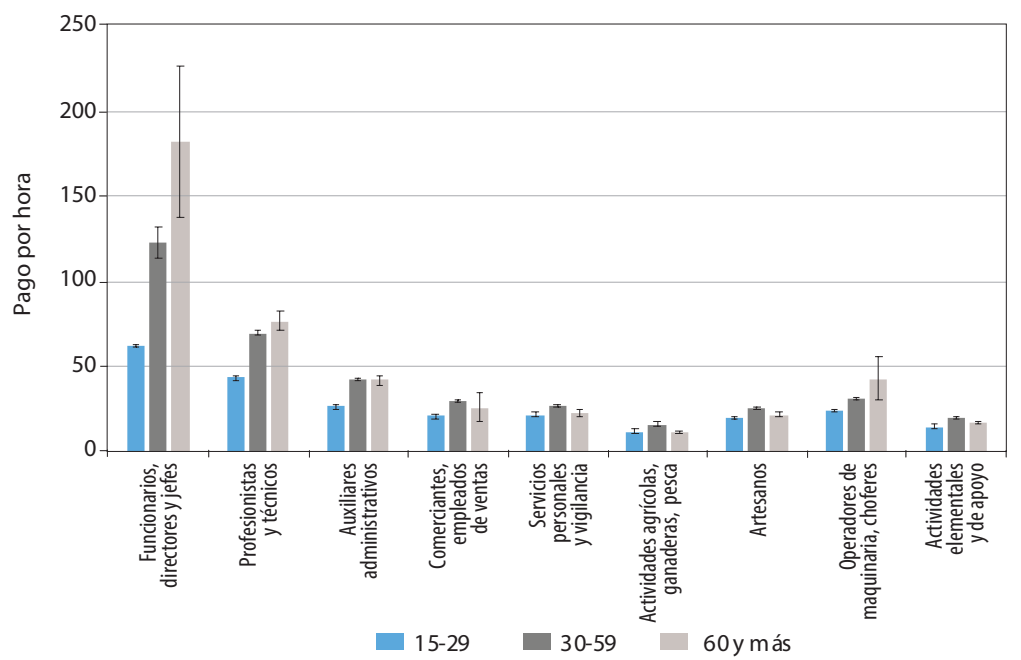

Fuente: Elaboración propia base en con datos del Coneval.

prejuicios sobre los salarios de los jóvenes en las encuestas nacionales no están disponibles, pues no se recopila información suficiente sobre habilidad, edad laboral, trayectoria y productividad o resultados. Y, en un nivel de análisis más complejo, de contar con esa información, habría que plantear si el sistema de selección y recompensa del mercado de trabajo es justo o necesita reconsiderarse para lograr mayor equidad o proteger a quienes han quedado marginados.

En cuanto a las posibilidades de ahorro, de acuerdo con la Encuesta Nacional de Inclusión Financiera 2015, solo 26 por ciento de los jóvenes que trabajan tiene Afore o fondo de retiro (la proporción aumenta a 31 por ciento entre los adultos), pero de los jóvenes que sí tienen Afore o fondo de retiro, la mitad declaró que no hace aportaciones voluntarias porque no le queda dinero para ahorrar (49\%). Aunque la proporción es similar en los adultos (48\%), es importante recordar que menos jóvenes tienen Afore y, aunque la tengan, el financiamiento del retiro es, en última instancia, individual. En cambio, los adultos tendrán asegurado un monto de pensión relacionado con su último salario cuando lleguen a la edad de retiro independientemente del número de años que cotizaron, de las aportaciones que hayan hecho sus patrones y del salario que hayan tenido en otros empleos a lo largo de su trayectoria laboral. De ahí la 
importancia de que los jóvenes estén en condiciones de ahorrar y hacer aportaciones a su Afore, pero las cifras indican que, en total, 87 por ciento de los que trabajan no tiene la posibilidad de acumular fondos para el retiro, ya sea porque no tiene la prestación o porque no le queda dinero para hacer aportaciones voluntarias (INEGI, 2015). Las estimaciones actuales establecen que apenas uno de cada diez trabajadores que pertenecen a la generación Afore recibirá una pensión superior al salario mínimo (Martínez Aviña, 2020) y, si no pudieron generar ahorros, lo único que los separa de la pobreza es que el salario mínimo alcance la línea de pobreza, cosa que apenas sucedió en 2019.

Entre los jóvenes que viven en hogares pobres, el ingreso corriente total per cápita es menor a su ingreso laboral individual. Es decir, esas personas pierden recursos al no poder emanciparse, pero sus ingresos son tan bajos que no les permiten cubrir los costos de independizarse y su calidad de vida material probablemente disminuiría si dejaran de vivir en el hogar de origen. Perder por quedarse pero no tener suficiente para irse afecta su capacidad de ahorro y dificulta la posibilidad de independizarse en el futuro (gráfica 4).

Ante el panorama de empleo (ingresos, seguridad social, inestabilidad laboral involuntaria) que enfrentan los jóvenes, si la experiencia —a la que no tienen

GRÁFICA 4. Comparación de la proporción de población por debajo de la línea de pobreza por tipos de ingreso y por grupos de edad

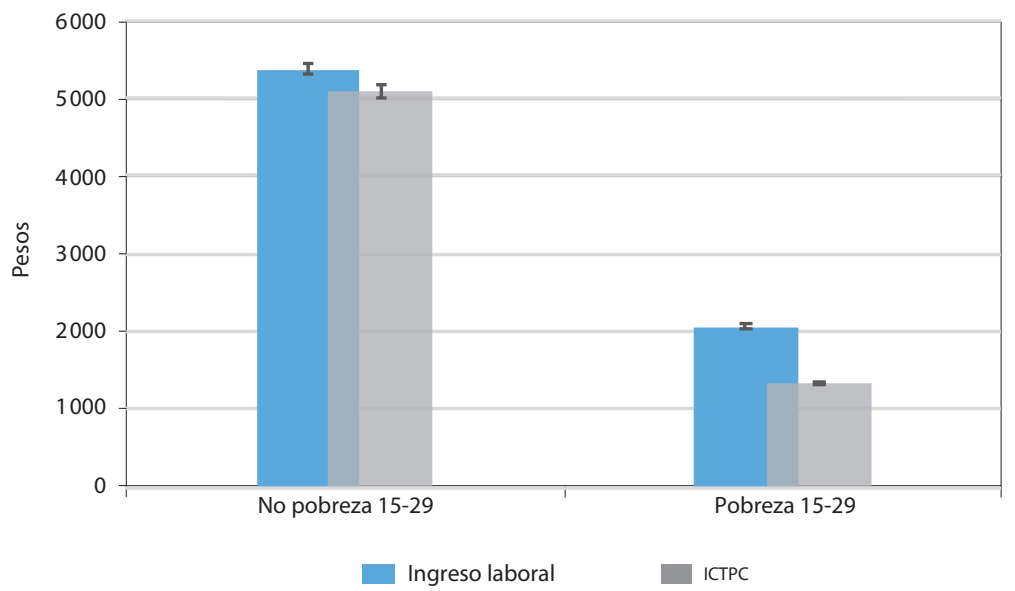

Fuente: Elaboración propia base en con datos del Coneval. 
acceso- - fuera un criterio objetivo para justificar la desigualdad en salarios respecto a los adultos, la carga del financiamiento para el retiro y la falta de ahorros personales es razón suficiente para considerar mecanismos regulatorios que compensen la desigualdad que genera el mercado laboral actual.

\section{EXPOSICIÓN AL RIESGO: TRANSICIONES Y DISCRIMINACIÓN}

Independientemente de los recursos institucionales y personales con los que cuente cada persona, los jóvenes pueden estar expuestos de manera más frecuente a eventos adversos, en comparación con otros grupos de población. Esto puede suceder de dos maneras. En primer lugar, la juventud es una etapa en la que típicamente se concentra una serie de transiciones vitales que pueden ser factores de riesgo para caer en pobreza (Vandecasteele, 2015). En segundo lugar, la discriminación o desigualdad de trato hacia los jóvenes puede provocar que se enfrenten a condiciones adversas que no existen para otros grupos de edad.

\section{Transiciones}

Las condiciones materiales de los jóvenes se ponen en juego de manera particular cuando ocurre una transición en el curso de vida y, de acuerdo con diversos estudios (Aassve et al., 2006; De Oliveira, 2006; Vandecasteele, 2015; Walther, 2006), el riesgo a la pobreza en la población joven se relaciona con las transiciones, no de manera intrínseca, sino por razones asociadas al momento y las condiciones en las que ocurren (Aassve et al., 2006; Vandecasteele, 2015), al diseño de la política pública y a la falta de mecanismos de protección social suficientes y adecuados. En México, ninguna de las transiciones más relevantes de la juventud está suficientemente protegida por las instituciones del Estado y, en muchos casos, las familias asumen la responsabilidad de cubrir este déficit, lo que coloca a los jóvenes en una posición vulnerable.

En sociedades con gran desigualdad económica, la dependencia familiar puede promover la existencia de regímenes duales de transición (Morrow, 2013; Nájera Catalán, 2016), donde los jóvenes que provienen de familias no pobres tienen menos riesgos durante la transición hacia la independencia porque permanecen protegidos durante más tiempo hasta que logran emanciparse en buenas condiciones o porque alcanzan mejores condiciones con mayor rapidez, gracias al financiamiento familiar o a que consiguen buenos empleos por las inversiones previas de sus familias en educación, capital social y capital cultural. En cambio, los jóvenes de familias en pobreza tienen transiciones más precarias y menos posibilidades de alcanzar mayores niveles educativos, de capacitación o de finan- 
ciamiento, lo que repercute en la calidad de su inserción laboral y en su proceso de independización de la familia de origen. Por ello, la protección del Estado es un factor decisivo para reducir la desigualdad en la vulnerabilidad asociada a las transiciones en esta etapa de la vida, que a su vez se convierte en un factor de transmisión intergeneracional de la pobreza.

\section{Discriminación directa y estructural}

La exposición al riesgo de la pobreza no solo se debe a las transiciones de la juventud sino a la discriminación directa y estructural que padecen los jóvenes. Sin embargo, el análisis de la vulnerabilidad de los jóvenes a la pobreza como un producto de la discriminación se dificulta, en primera instancia, porque la desigualdad en el trato está normalizada o se confunde con fenómenos correlacionados. El hecho de que la juventud se quita con el tiempo constituye una dificultad adicional para el análisis, pues el trato que reciben los jóvenes cambia cuando se insertan en la adultez y, como resultado de este proceso del curso de vida, la discriminación puede parecer una casualidad temporal y no un problema estructural.

Se podría objetar que, en algunos casos, las desventajas que enfrentan los jóvenes no son producto de la discriminación sino de factores macroeconómicos que no perjudican a los jóvenes por su edad, sino por la cohorte a la que pertenecen o por las coyunturas propias de un periodo determinado. Es cierto que los procesos económicos que resultan en adversidades para los individuos casi nunca tienen a los jóvenes como su objetivo intencional. Pero si dichas crisis o reformas hubieran ocurrido en otra época, los más afectados en las sociedades adultocéntricas seguirían siendo los jóvenes pues son el grupo con menos protección institucional y una carga más onerosa en los esquemas de dependencia familiar. Esta situación es producto de la desigualdad estructural en la que diferentes actores sociales tienen diferente posición y acceso a mecanismos para defender sus intereses. En primera instancia, ante una coyuntura, se prioriza, pongamos por caso, garantizar los fondos para pagar las pensiones y jubilaciones de quienes hoy son adultos o mayores, por encima de garantizar salarios dignos para quienes hoy son jóvenes. En segunda instancia, si una crisis produce incrementos en el desempleo, las leyes otorgan mayor protección a los trabajadores formales sin importar el grupo etario al que pertenecen, pero el sistema previamente había colocado a los jóvenes en el empleo informal de manera desproporcionada. Las adversidades inciden en la juventud porque está desprotegida al vivir en una sociedad adultocéntrica y aquí radica la discriminación. 
No obstante, aunque la discriminación termine, las secuelas permanecen y los efectos de, por ejemplo, una mala inserción laboral se pueden observar hasta una década después (Kahn, 2010; OIT, 2015) y afectar las condiciones laborales en empleos subsecuentes (OIT, 2015). Es decir, la desigualdad en el trato tiene efectos nocivos que se mantienen a lo largo de mucho más tiempo y el hecho de que todos los jóvenes se convierten en adultos hace difícil trazar la conexión entre las desventajas y la discriminación sufridas en el pasado con las consecuencias que tienen en la siguiente etapa de la vida. En cambio, es mucho más sencillo observar otros factores que permanecen, como el nivel educativo o la experiencia laboral y atribuirles la causalidad de la desventaja a estos. Introducir la noción de adultocentrismo y la perspectiva de la discriminación en el análisis de la situación de los jóvenes facilita visibilizar y distinguir el curso de vida, los eventos coyunturales y los factores estructurales.

\section{Resultados}

En México, la transición de la escuela al trabajo no forma parte de la protección social institucionalizada, pues no existen mecanismos que vinculen a los estudiantes con los empleadores o que los protejan del desempleo al salir del sistema educativo. ${ }^{7}$ Por otro lado, los jóvenes en la actualidad se enfrentan a una desconexión importante entre el sistema educativo y las necesidades del mercado de trabajo (que se refleja en el desempleo y subempleo), a una baja calidad en la educación (sobre todo en la educación pública, pero no únicamente) (OCDE, 2016; OCDE, 2013) y a una tendencia a la baja en los rendimientos de la educación (Szekely y Flores, 2018). En 2019, 50 por ciento de los desempleados tenía educación media superior y universitaria, cifra que se eleva a 62 por ciento en el grupo de 20 a 29 años. $^{8}$ El desempleo entre las personas con los niveles educativos más altos ha aumentado con el paso del tiempo, pues en 2005 las cifras eran 31 por ciento para el total de la población y 47 por ciento para los jóvenes.

Así, el riesgo en el tránsito de la escuela al trabajo se alimenta de la ausencia de mecanismos para mejorar la conexión entre el contenido de la educación, las habilidades adquiridas y las necesidades del mercado laboral o para cubrir la

\footnotetext{
${ }^{7}$ El programa Jóvenes Construyendo el Futuro es la primera iniciativa a nivel nacional que busca mejorar la inserción de los jóvenes al mercado de trabajo ofreciendo capacitación y, como efecto secundario, redes o conexiones sociales que faciliten una eventual contratación. El programa ofrece una beca a los jóvenes a cambio de que empresas e instituciones los capaciten para el empleo durante un plazo de un año. Sin embargo, este programa empezó a operar apenas en 2019.

${ }^{8}$ Las cifras provienen de la Encuesta Nacional de Ocupación y Empleo (ENOE) (INEGI, 2021).
} 
falta de información (o capital social) de los jóvenes sobre los empleos disponibles, en comparación con un adulto.

Aunado al desempleo, la mayor parte de los jóvenes asalariados en México se encuentra en situaciones laborales de alta precariedad (De Oliveira, 2006). Ante la ausencia de protección frente al desempleo o el trabajo precario y la poca eficiencia de la educación como medio para asegurar la incorporación adecuada al mercado laboral, las familias cubren los riesgos asociados a la inserción como salarios insuficientes, horarios excesivos, gastos derivados de la falta de prestaciones, entre otros. Por ejemplo, el porcentaje de jóvenes cuyos ingresos laborales están por debajo de la línea de pobreza es mayor que el de los adultos (38 y 28\%, respectivamente).

El adultocentrismo también es visible dentro del mismo grupo de edad. Los jóvenes que se encuentran en una posición familiar subordinada tienen mayor probabilidad de tener ingresos laborales inferiores a la línea de pobreza que los jóvenes que son jefes de familia. En 2014, 56 por ciento de los jóvenes que son nietos y 48 por ciento de los que son hijos del jefe del hogar tuvieron ingresos laborales por debajo de la línea de pobreza, mientras que el porcentaje se reduce a 23 por ciento entre los que son jefes de familia. Esto puede ocurrir por diferentes causas: puede ser que los jóvenes no se independizan cuando sus ingresos son insuficientes; puede ser que quienes se ven forzados a asumir el liderazgo de la familia también se ven presionados a negociar salarios más altos; o puede ser que la sociedad, en el ámbito laboral al menos, favorece a los jefes de familia por encima de los dependientes, como sugiere Weller (2007). Sin embargo, la proporción de jóvenes con ingresos laborales por debajo de la línea de pobreza siempre es mayor que entre los adultos.

Depender de la familia para cubrir los riesgos de una transición complicada de la escuela al mercado laboral dificulta a su vez otra transición: emanciparse. La emancipación es un proceso que involucra la independencia económica de la unidad doméstica de origen y la conformación de una nueva unidad, con todos los gastos iniciales que esto implica. Emanciparse puede coincidir o no con la primera unión, pero en caso de hacerlo, la distribución de los costos entre dos personas facilita el proceso.

Actualmente no hay mecanismos para proteger la emancipación de la caída en pobreza y los jóvenes que no cuentan con los recursos suficientes deben elegir entre enfrentar el riesgo de caer en pobreza o quedarse en casa de sus padres, postergando la unión o viviendo con sus parejas en alguno de los hogares de origen. En México, la proporción de jóvenes que viven solos es mínima: menos 
de 2 por ciento entre los hombres y menos de 1 por ciento entre las mujeres. ${ }^{9}$ Por sí solas, las encuestas nacionales no permiten saber si esto se debe a prácticas culturales o a la imposibilidad económica de independizarse, pero los datos sugieren que solo se independiza quien puede, no quien quiere, pues la prevalencia de pobreza es de 11 por ciento entre los jóvenes que viven solos y 46 por ciento entre los que no viven solos. ${ }^{10}$

Independientemente de las prácticas culturales, la emancipación no parece ser una opción económicamente accesible para la juventud mexicana, considerando que alrededor de la mitad de los jóvenes que no son jefes de familia tienen ingresos laborales por debajo de la línea de pobreza. Por otro lado, permanecer en el hogar de origen tiene costos económicos que podrían representar un obstáculo adicional a la emancipación. El ingreso laboral promedio de los jóvenes que no se encuentran en pobreza es prácticamente igual a su ingreso corriente total per cápita, ${ }^{11}$ lo que indica que no hay pérdidas asociadas a quedarse en casa de los padres. Por el contrario, entre los jóvenes en pobreza que trabajan, el ingreso laboral promedio es considerablemente mayor al ingreso corriente total per cápita: los jóvenes en pobreza reciben 66 por ciento de lo que aportan a la unidad doméstica, mientras que los no pobres reciben 97 por ciento. Esto sugiere que los jóvenes en pobreza se beneficiarían si se emanciparan. Sin embargo, el monto del ingreso laboral promedio es de 2042 pesos mensuales (5397 entre los no pobres), que no alcanza para cubrir los gastos de una vivienda.

Todo lo anterior sugiere que se emancipa quien puede hacerlo o quien se ve forzado a hacerlo, pero permanecer en el hogar de origen no equivale a una posición ventajosa porque los recursos individuales se reparten y porque los recursos de la familia de origen determinan la seguridad con la que ocurre la transición, lo cual frena las posibilidades de movilidad social ascendente de los jóvenes con menos recursos.

Además, no hay créditos de vivienda accesibles o con montos suficientes destinados a los jóvenes. En la actualidad, la mayoría de los créditos tienen requisitos prohibitivos para la juventud, como tener un empleo formal para

${ }^{9}$ Con datos de la enoe 2019, primer trimestre (INEgi, 2019).

${ }^{10}$ En países como España e Italia se ha observado que postergar la emancipación tiene un efecto protector ante la pobreza (Aassve et al., 2006) y los estudios que se han realizado con datos longitudinales en Europa encuentran que dejar la casa de los padres es un factor de riesgo significativo y considerable (Vandecasteele, 2015).

${ }^{11}$ Datos de la ENIGH 2014. Se decidió utilizar los datos de 2014 dado que la información disponible para 2016 y 2018 se basa en un modelo estadístico para la comparabilidad que estima el ingreso y no en observaciones. Véase Coneval (2016). 
comprobar ingresos o para acceder a créditos de las instituciones gubernamentales, salarios altos para acceder a montos suficientes como para adquirir una propiedad, entre otros. Esto puede considerarse una forma de discriminación institucionalizada.

Tener hijos es probablemente la transición más riesgosa tanto para los jóvenes como para la transmisión intergeneracional de las condiciones de pobreza. En este sentido, la planificación familiar se vuelve muy relevante, pero en México la salud y la educación sexual y reproductiva reciben una atención marginal y rara vez están específicamente diseñadas para los jóvenes, que deberían considerarse un grupo de usuarios particularmente importante. Uno de los temas centrales en este ámbito es la anticoncepción y la Encuesta Nacional de la Dinámica Demográfica (Enadid) ${ }^{12}$ muestra que existen vacíos en las políticas y servicios del Estado que obstaculizan la posibilidad de los jóvenes de controlar su vida sexual y acceder a los servicios especializados. Por ejemplo, aunque la provisión de métodos anticonceptivos es parte de los servicios de salud públicos, no parece cubrir las necesidades de las mujeres jóvenes. Entre las que ya iniciaron su vida sexual, 19 por ciento nunca ha utilizado un método anticonceptivo, cifra que resulta alarmante tanto por el riesgo de transmisión de enfermedades como por la falta de agencia en el embarazo. Entre aquellas que reportaron haber tenido relaciones sexuales en el último mes, el método anticonceptivo más popular son los condones (40\%), seguido del DIU (26\%) y los implantes subdérmicos (13\%). Aunque los primeros se distribuyen a través de diferentes instituciones públicas, la mayoría de las jóvenes o sus parejas los obtienen en farmacias o tiendas de autoservicio, lo cual indica que hay un problema en las políticas de distribución, en la accesibilidad de los servicios o en la confianza en la calidad de los anticonceptivos que se distribuyen, por mencionar solo algunas posibilidades. Los otros dos métodos se obtienen a partes casi iguales en el sistema público y el privado, lo que habla de las limitaciones de la cobertura de los servicios del Estado (gráfica 5).

Por otro lado, entre las jóvenes que alguna vez han estado embarazadas, 15 por ciento han tenido un aborto, aunque la causa del aborto no se reporta ni la institución en que fueron atendidas (gubernamentales o privadas). Aunque en la actualidad solo la Ciudad de México y Oaxaca han despenalizado el aborto por

\footnotetext{
${ }^{12}$ Todas las cifras de este apartado provienen de la Encuesta Nacional de la Dinámica Demográfica 2018 (INEGI, 2018), a menos que se indique lo contrario. Esta encuesta solo recaba información de uso de anticonceptivos entre las mujeres, por lo que no se hablará de los hombres. Aunque este sesgo de género en la recopilación de la información puede ser comprensible en términos metodológicos, no deja de evidenciar la desigualdad entre hombres y mujeres en el ámbito de la sexualidad y la anticoncepción.
} 
GRÁFICA 5. Lugar de obtención del anticonceptivo utilizado actualmente en jóvenes con vida sexual activa en el último mes

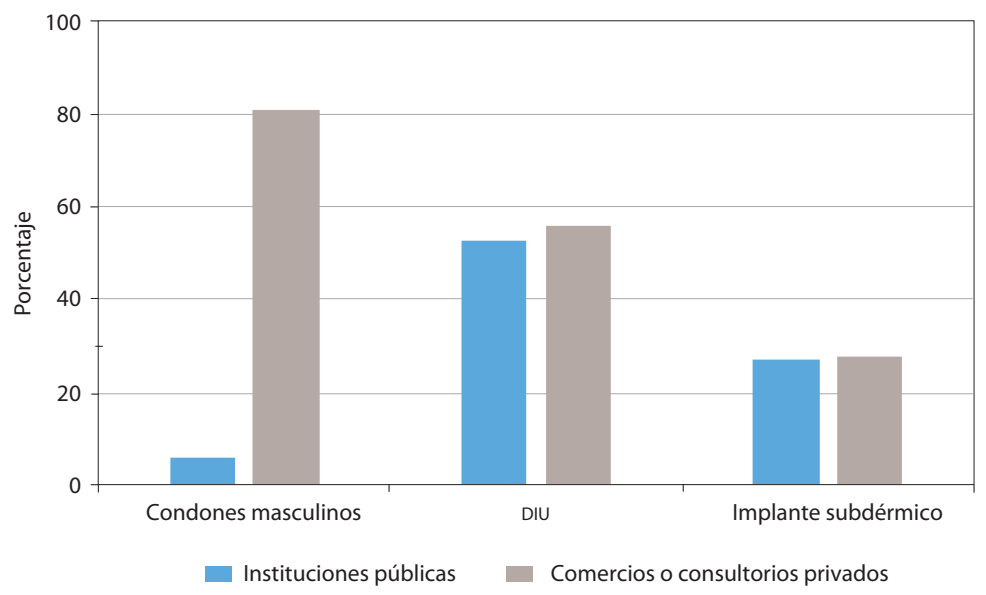

Fuente: Elaboración propia con base en datos de la Enadid (INEGI, 2018).

voluntad de la mujer, la interrupción del embarazo es legal en todo el país cuando se trata de casos de violación. No existen cifras oficiales sobre los abortos por violación, pero organizaciones civiles especializadas han reportado que de 111413 denuncias por violación sexual recibidas entre 2009 y 2016, sólo se han practicado 63 procedimientos de aborto por violación en las instituciones públicas ${ }^{13}$ (GIRE, 2017) y la enorme brecha entre ambas cifras sugiere que hay un gran incumplimiento del Estado en garantizar el acceso al aborto legal. El Estado no asume su responsabilidad de que los jóvenes, especialmente las mujeres, tengan hijos en las mejores condiciones y de manera deseada o planificada porque no hay educación sexual, no hay cobertura suficiente y adecuada de anticonceptivos, no hay acceso al aborto en caso de violación (que es legal) y no hay aborto voluntario seguro a nivel nacional.

Por último, la mater/paternidad tampoco está suficientemente protegida. En México, la mayor parte de los nińos nacen durante el periodo de juventud de sus padres. De todos los nacimientos registrados en 2016, sin importar si fueron el primer o el último hijo, 71 por ciento fueron de mujeres menores a 29 años y 51 por ciento de hombres menores a 29 años (INEGI, 1985-2020). Si bien exis-

\footnotetext{
${ }^{13}$ Secretarías de salud locales y federal, IMss e Issste.
} 
ten mecanismos institucionales que ofrecen cierta protección —como la prohibición de despido por embarazo, las licencias de maternidad o (recientemente) de paternidad, la prestación laboral de guarderías o la deducibilidad de los gastos en colegiaturas-, también es cierto que estos mecanismos están asociados al empleo formal con prestaciones, al cual los jóvenes tienen considerablemente menor acceso que los adultos.

Entre las jóvenes que trabajan, 66 por ciento declararon no tener la prestación de incapacidad por maternidad. ${ }^{14}$ Aunque el porcentaje de trabajadores con la prestación de incapacidad por maternidad es casi el mismo para jóvenes y adultas ( 22 y $24 \%$, respectivamente), la cobertura real de la prestación, para la población total sin importar su estatus laboral, solo abarca a 13 por ciento de la población joven, pero alcanza 19 por ciento entre la población adulta. Esto es resultado del vínculo de la protección social con el empleo formal y de la exclusión de los jóvenes de este último.

La incapacidad se refiere a otorgar tiempo de cuidados perinatales con goce de sueldo de manera que las nuevas madres y padres puedan cuidar a sus hijos y recuperarse del parto sin perder sus ingresos. ${ }^{15} \mathrm{Y}$, en este sentido, se podría argumentar que solo los trabajadores requieren esta prestación, pues son los que tienen un ingreso laboral que perder (en lugar de pensar en una cobertura universal independientemente de si la persona es económicamente activa). Este argumento es cuestionable porque la llegada de un hijo requiere de ingresos y el Estado debería velar por las condiciones de vida de sus miembros más pequeños. Pero aun si seguimos una lógica absolutamente individualista donde los padres son los únicos responsables de las condiciones de vida de sus hijos, sin importar si fueron libres de elegir el momento y las condiciones en que los tuvieron, esta perspectiva no es tan válida en el caso de otros servicios asociados a la crianza, como las guarderías o estancias infantiles.

Incluso los jóvenes que no trabajan y tienen hijos necesitan de guarderías, ya sea para estudiar, para buscar empleo o para realizar otras actividades. Por lo tanto, las madres y padres jóvenes deberían contar con guarderías independientemente de su estatus laboral, cosa que no sucede. Entre los jóvenes que trabajan, solo 8 por ciento dijeron tener la prestación de guardería, pero en realidad solo

\footnotetext{
${ }^{14}$ Datos de la ENIGH 2014. Se decidió utilizar los datos de 2014 dado que la información disponible para 2016 y 2018 se basa en un modelo estadístico para la comparabilidad que estima el ingreso y no en observaciones. Véase Coneval (2016).

${ }^{15}$ En todo caso habría que reflexionar sobre si basta con el tiempo y el mismo ingreso para cuidar a un recién nacido, especialmente como madre o padre primerizo.
} 
5 por ciento de la población juvenil total tiene acceso a esta prestación, aunque les corresponden 71 por ciento de los nacimientos, como se mencionó arriba (INEGI, 2014).

La vinculación de las prestaciones al empleo formal y la desigualdad de género en el acceso a ellas cobra relevancia porque, de las mujeres jóvenes que registraron a un hijo durante 2016, solo 17 por ciento tenía un empleo al momento del registro y 75 por ciento no lo tenía (las proporciones se invierten en el caso de los hombres a 88 y 4\%, respectivamente). El hecho de que la proporción de madres jóvenes de recién nacidos que no trabajan fuera de casa sea tan alta sugiere dos cosas. Una es que las jóvenes optan o se ven obligadas a dejar el empleo, al menos temporalmente, cuando tienen hijos (sin importar si es el primero o no), debido a que absorben la mayor parte de las tareas de cuidados. La otra es que las prestaciones laborales, en caso de existir, no bastan para satisfacer las necesidades de las madres trabajadoras, ya sea por falta de acceso o por las barreras para utilizarlas. ${ }^{16}$ Claramente el diseño de la protección a esta transición no es el adecuado porque no atiende a las necesidades de quienes deberían ser su principal población objetivo: los jóvenes.

El resultado, de nuevo, es que las familias absorben la parte de la protección que el Estado no alcanza a cubrir. Las madres dejan el empleo para proveer cuidados o se trasladan al empleo informal para tener mayor flexibilidad (Coneval, 2018 b) y la familia extendida funge como guardería. Por otro lado, este es un punto de inflexión en la desigualdad salarial entre hombres y mujeres y exacerba la desigualdad en el tiempo dedicado al trabajo no remunerado. Cuando las mujeres se convierten en madres, su trayectoria laboral se ve afectada por las labores de cuidado de los hijos, que recaen predominantemente en ellas (Kleven $e t$ al., 2018).

Por último, además de lo ya mencionado, los jóvenes se encuentran en una posición de vulnerabilidad particular dentro de las mismas familias. Como se dijo, las transiciones de la juventud que no están protegidas por el Estado quedan a merced de la protección familiar, pero eso implica que las necesidades de los jóvenes se supediten a las necesidades de otras personas o a las limitaciones en los recursos de dicho núcleo. México es una sociedad colectivista donde los intereses individuales tienden a sujetarse a los intereses de los grupos de pertenencia, como la familia (Hofstede, 2001; Triandis et al., 1988). La combinación de la

\footnotetext{
${ }^{16}$ No es inusual que los empleadores consideren el uso de las prestaciones de este tipo como algo poco profesional, como muestra de poco compromiso laboral o como abuso de parte de las y los trabajadores.
} 
ausencia de protección institucional, las dinámicas culturales colectivistas y el adultocentrismo de la sociedad puede incrementar el riesgo que enfrentan los jóvenes en sus transiciones en el curso de vida porque se espera deferencia de los jóvenes hacia los adultos (véase Green et al., 2005; Laca et al., 2012; Triandis, 2001). Los jóvenes que no tienen acceso a recursos monetarios e institucionales para enfrentar la vida independiente, de cierta forma están sometidos a un estado de juvenilización/infantilización y minusvalía respecto a aquellos adultos que los mantienen total o parcialmente y que, por ello, controlan el acceso de los jóvenes a los recursos familiares o pueden ejercer influencia sobre sus decisiones y actividades. Por ejemplo, los jóvenes con menores recursos interrumpen sus estudios de manera más temprana por la necesidad de aportar al ingreso familiar o solventar los gastos de hijos menores, aunque no son sus hijos y, por lo tanto, no son su responsabilidad. Las presiones derivadas de la dependencia pueden tener efectos en la forma en que ocurren las transiciones y, por ende, en la vulnerabilidad de los jóvenes a la pobreza.

Las mismas instituciones del Estado han reconocido que la dependencia familiar es un problema que debe evitarse, discutiendo particularmente el caso del acceso a la salud (Coneval, 2012). Cuando un joven tiene acceso indirecto a los servicios de salud, está expuesto a perder un servicio vital y el ejercicio de sus derechos por una variedad de causas sobre las que no tiene control, como el desempleo del derechohabiente.

\section{IMPLICACIONES PARA LA POLÍTICA PÚBLICA}

Como se vio en los apartados previos, los jóvenes se encuentran en mayor riesgo de pobreza debido a las condiciones de fragilidad y exposición al riesgo. El análisis sugiere que la pobreza juvenil está invisibilizada y latente, y es probable que se manifieste con toda crudeza en etapas posteriores de la vida si no se toman medidas para evitarlo. De ahí surgen algunas consideraciones para el diseño de política pública dirigida a este grupo de población que sería importante rediseñar en función de los riesgos que los jóvenes enfrentan para su bienestar presente y futuro.

En términos de las fuentes de fragilidad, un factor muy preocupante es el acceso a la seguridad social. El diseño actual del acceso a la seguridad social por medio del trabajo formal está desprotegiendo a los jóvenes, de manera que se necesitan nuevas estrategias para garantizar el acceso. Una es establecer incentivos y facilidades para la formalización de los jóvenes específicamente, que deben, al mismo tiempo, impedir que se les contrate en los puestos de menores ingresos y 
alta rotación. Otra es cambiar el diseño de la seguridad social para permitir que más personas accedan a ella. La seguridad social debería ser universal — no necesariamente gratuita - y se pueden diseñar esquemas de contribución obligatorios y progresivos que dependan del nivel socioeconómico de la persona y sean independientes de su estatus laboral para que toda la sociedad contribuya y facilite el financiamiento del acceso de los jóvenes con menores ingresos a la protección institucional.

Además del acceso a la seguridad social, es necesario rediseñar los fondos de pensiones y los servicios de salud. En el primer caso, se debe reducir la triple carga de los jóvenes (menor acceso a fondos para el retiro, financiamiento individual y contribución a pensiones de generaciones previas mediante impuestos) adoptando estrategias redistributivas dentro de los fondos de pensiones, por ejemplo, establecer un máximo para el monto de las pensiones de las generaciones previas a las Afores que reduzca la carga del sistema de pensiones y permita implementar medidas compensatorias para las nuevas generaciones, como transferencias complementarias a los fondos de pensiones o a los ingresos en casos donde las aportaciones patronales o los salarios sean demasiado bajos durante la juventud.

En cuanto a los servicios de salud, se debe prestar atención a las necesidades de los jóvenes y promover la atención preventiva, la nutrición adecuada y la salud sexual y reproductiva. Esto permite responder a las necesidades de esta etapa de la vida y asegurar mejores condiciones de salud en etapas posteriores, que reduzcan el riesgo de un gasto catastrófico en salud o la incapacidad por enfermedades crónico-degenerativas prevenibles. Esto, además, irá reduciendo gastos al sistema público de salud paulatinamente.

En cuanto al acceso a bienes mediante deuda, una posible medida compensatoria de la triple carga que impone el esquema actual de financiamiento para las pensiones puede ser facilitar el acceso a créditos para la compra, construcción o remodelación de vivienda durante los primeros años de la adultez, acompañados de servicios públicos de asesoría que les ayuden a planear y dar el mejor uso al préstamo que reciban. También se pueden establecer esquemas de créditos de montos menores con condiciones favorables para este grupo de edad.

En materia de protección a las transiciones, el Estado tiene mucho espacio de acción. Proteger el ingreso al mercado laboral de cada generación es importante para garantizar una mejor trayectoria laboral y para permitir la capitalización de la inversión en educación. Esto puede hacerse mediante incentivos a los empleadores para que contraten personas jóvenes en puestos de diferentes niveles de jerarquía (no sólo los puestos de salarios más bajos) o con cuotas de edad en las 
plantillas más grandes. También se deben eliminar las condiciones de contratación y despido que coloquen a los jóvenes en mayor desventaja. Por ejemplo, el hecho de que la liquidación que se entrega a un trabajador al despedirlo aumenta con los años que lleva trabajando para el mismo empleador coloca a los adultos y los mayores en ventaja respecto a los jóvenes. La medida cumple una función importante - desalentar el despido, particularmente cuando la persona se acerca a la edad de jubilación-, pero no debe exponer a los jóvenes a ser despedidos con mayor facilidad. En este sentido, se podría implementar un esquema compensatorio de multas que penalice a los empleadores cuando despidan a los jóvenes de manera desproporcionada.

La transición a la mater/paternidad es la más riesgosa, en especial para las mujeres, que pueden ver penalizados sus ingresos y proyectos de vida por el solo hecho de tener hijos (Kleven et al., 2018). En este caso, es imprescindible realizar mayores esfuerzos para que la reproducción sea verdaderamente libre, elegida y protegida. Esto implica, como ya vimos, primero, la educación sexual y reproductiva oportuna, accesible y adecuada para toda la sociedad, en particular para hombres y mujeres adolescentes. Segundo, la provisión y capacitación para el uso adecuado de los anticonceptivos que más utilizan los jóvenes y la posibilidad de elegir el aborto de manera segura y gratuita en todo el país. Tercero, la ampliación de la cobertura de servicios y prestaciones relacionadas con la crianza, como las licencias de paternidad para los hombres — que idealmente deberían cubrir varias semanas, en lugar de unos cuantos días, para que ellos puedan involucrarse en la ardua tarea de cuidar de un recién nacido- y los servicios de guardería (para ambos padres) que permiten que las madres sigan con sus proyectos laborales o de vida independientemente de la maternidad.

Además, también hay un amplio margen para proteger las posibilidades de emancipación para que quienes deseen independizarse y requieran apoyo, accedan a él. Esto se puede lograr de diferentes maneras. Una es promover la oferta de créditos para los jóvenes a través de instituciones como el Instituto del Fondo Nacional de la Vivienda para los Trabajadores (Infonavit). Otra es limitar los requisitos que se pueden imponer a los jóvenes para rentar una vivienda y ofrecer apoyos (transferencias o créditos) para el pago de los depósitos iniciales. Asimismo, implementar un sistema de cuidados para personas mayores o con discapacidad tendría efectos positivos en las trayectorias de las mujeres jóvenes, a quienes usualmente se asignan las tareas de cuidados y por ello pueden tener posibilidades de emancipación limitadas o trayectorias educativas y laborales interrumpidas. 
Finalmente, es imprescindible comenzar a cuestionar el esquema adultocéntrico que predomina en la sociedad, promoviendo — por medio de campańas de difusión - la igualdad entre jóvenes y adultos y el respeto a los derechos de los primeros. La política social que tenga por objetivo revertir la desigualdad estructural debe concebirse con enfoque igualmente estructural y combatir de manera intensiva la discriminación normalizada que pasa desapercibida en una multitud de acciones cotidianas.

En síntesis, es importante diseñar la política pública con una perspectiva más integral de las necesidades de este grupo de población y, sobre todo, de las consecuencias a largo plazo de las condiciones que tienen en la actualidad. Esto implica, entre otras cosas, orientar la política pública no solo en función de las cifras de pobreza actual entre los jóvenes — que no muestran un panorama distinto al promedio nacional y no refleja las necesidades específicas de esta etapa de la vida-, sino en función de los factores de riesgo que enfrentan. Tal enfoque permitirá contar con una política social más coherente, integral y eficiente que sea capaz de enfocar los recursos, los riesgos y las transiciones característicos de este grupo etario.

\section{CONCLUSIONES}

Este artículo revisa la vulnerabilidad a la pobreza de los jóvenes en perspectiva comparada con los adultos, a partir del análisis de diferentes factores de fragilidad y exposición al riesgo que son desiguales entre ambos grupos etarios.

Se encontró una desprotección sistemática a las transiciones que caracterizan a la juventud y que constituyen un factor de riesgo a la pobreza y de desigualdad respecto a los adultos, así como limitaciones sistemáticas en el acceso a los recursos y mecanismos de protección que les permitirían evitar la pobreza o la vulnerabilidad a ella. También se planteó la forma en que la discriminación alimenta e invisibiliza estas desventajas sistemáticas, lo cual podría influir en el hecho de que la política social dirigida a los jóvenes sea tan escasa y esté poco organizada.

El análisis de la vulnerabilidad que produce la desigualdad estructural muestra que el riesgo de los jóvenes tiene dos facetas. A corto plazo, existe el riesgo directo por no tener acceso a los recursos para evitar la pobreza como individuos - por sus propios medios o con apoyo institucional—y, además, el riesgo indirecto al depender de recursos familiares que suplen la ausencia de políticas sociales eficientes. La desventaja y los riesgos que genera la falta de protección institucional se disimulan en una relativa red de seguridad familiar que, en el peor de los casos, reproduce la inmovilidad social predominante en México, donde el origen es destino. 
Por otro lado, a largo plazo, existe el riesgo de caer en pobreza en el futuro gracias a la debilidad de los sistemas de seguridad social o la falta de cobertura, en particular en las transiciones que típicamente ocurren en el periodo de juventud, y las consecuencias que la desprotección acarrea a lo largo del tiempo. Los resultados de la desigualdad estructural y la discriminación directa pueden confundirse con los efectos de externalidades como las crisis económicas. Sin embargo, la desventaja de los jóvenes no proviene de vivir un momento macroeconómico malo sino de ser joven en ese periodo y no tener acceso a la protección institucionalizada que tienen otros grupos de edad.

Es previsible que, los riesgos derivados de fragilidades y exposiciones desiguales al paso del tiempo no podrán ser contenidos por las estrategias coyunturales a las que los jóvenes recurren. Esto probablemente derive en pobreza en la etapa adulta o en la vejez, no por las circunstancias de ese momento futuro sino por la falta de protección desde la juventud. Esa pobreza no se llamará pobreza juvenil, pero sin duda proviene de la vulnerabilidad impuesta durante la juventud.

Finalmente, es importante cambiar el enfoque político respecto al trato hacia los jóvenes, en el que aún resuena la lógica del aprovechamiento del bono demográfico, entendida casi como la explotación eficiente de un recurso perecedero del país. Los recursos perecederos se deben consumir pronto y ser digeridos para aprovechar sus nutrientes. La sociedad, y en particular el mercado laboral, consumen y digieren jóvenes con sueños, con aspiraciones que se desvanecen demasiado rápido. La sociedad mexicana se beneficiaría en conjunto si cambiara la lógica de "aprovechar" la juventud por una concepción más horizontal y sensible donde se piense que si a los jóvenes les va bien, a todos nos irá mejor. El análisis presentado aquí muestra la importancia de generar políticas que reduzcan la vulnerabilidad si se quiere reducir el riesgo a la pobreza y caminar hacia una sociedad más democrática, incluyente y equitativa. G్

\section{REFERENCIAS}

Aassve, A., M. Iacovou y L. Mencarini (2006), "Youth Poverty and Transition to Adulthood in Europe”, Demographic Research, 15(2), pp. 21-50, DoI: https://doi.org/10.4054/ DemRes.2006.15.2.

Busso, G. (2001), "Vulnerabilidad social: Nociones e implicancias de políticas para latinoamerica a inicios del siglo xxi", presentado en el Seminario Internacional "Las Diferentes Expresiones de la Vulnerabilidad Social en América Latina y el Caribe", Santiago de Chile, 20 y 21 de junio.

Conapred (Consejo Nacional para Prevenir la Discriminación) (2011), Encuesta Nacional 
sobre Discriminación en México (Enadis 2010), Ciudad de México, Conapred, disponible en: https://www.conapred.org.mx/userfiles/files/Enadis-2010-RG-Accss-002.pdf [fecha de consulta: 5 de agosto de 2020].

Conapred (Consejo Nacional para Prevenir la Discriminación) (2018a), Encuesta Nacional sobre Discriminación 2017: Prontuario de resultados, Ciudad de México, Conapred, disponible en: https://www.conapred.org.mx/documentos_cedoc/Enadis_Prontuario_Ax_1.2.pdf [fecha de consulta: 5 de agosto de 2020].

Conapred (Consejo Nacional para Prevenir la Discriminación) (2018b), Ficha temática: Personas jóvenes, Ciudad de México, Conapred, disponible en: https://www.conapred. org.mx/userfiles/files/FichaTematica_Jovenes.pdf [fecha de consulta: 5 de agosto de 2020].

Conapred (Consejo Nacional para Prevenir la Discriminación) (2019), Discriminación personas jóvenes, Ciudad de México, Conapred, disponible en: https://www.conapred. org. $\mathrm{mx} /$ index.php? contenido=pagina\&id=186\&id_opcion=184\&op $=184$ [fecha de consulta: 28 de marzo de 2019].

Coneval (Consejo Nacional de Evaluación de la Política de Desarrollo Social) (2012), Pobreza y género en México: Hacia un sistema de indicadores, Ciudad de México, Coneval, disponible en: https://www.coneval.org.mx/Informes/Coordinacion/INFORMES_Y_ PUBLICACIONES_PDF/PobrezayGeneroenweb.pdf [fecha de consulta: 5 de agosto de 2020].

Coneval (Consejo Nacional de Evaluación de la Política de Desarrollo Social) (2014a), La pobreza en la población indígena de México, 2012, Ciudad de México, Coneval.

Coneval (Consejo Nacional de Evaluación de la Política de Desarrollo Social) (2014b), Medición de la pobreza, 2014, Ciudad de México, Coneval, disponible en: https://www. coneval.org.mx/Medicion/MP/Paginas/Pobreza-2018.aspx [fecha de consulta: 5 de agosto de 2020].

Coneval (Consejo Nacional de Evaluación de la Política de Desarrollo Social) (2014c), Pobreza y género en México: Hacia un sistema de indicadores, 2008-2012, Ciudad de México, Coneval.

Coneval (Consejo Nacional de Evaluación de la Política de Desarrollo Social) (2016), Pobreza en México: Resultados de pobreza en México 2016 a nivel nacional y por entidades federativas, Ciudad de México, Coneval, disponible en: https:/www.coneval.org.mx/ Medicion/MP/Paginas/Pobreza_2016.aspx [fecha de consulta: 5 de agosto de 2020].

Coneval (Consejo Nacional de Evaluación de la Política de Desarrollo Social) (2018a), Estudio diagnóstico del derecho a la vivienda digna y decorosa 2018. Ciudad de México, Coneval.

Coneval (Consejo Nacional de Evaluación de la Política de Desarrollo Social) (2018b), 
Estudio diagnóstico del derecho al trabajo, 2018, Ciudad de México, Coneval, disponible en: https://coneval.org.mx/Evaluacion/IEPSM/Documents/Derechos_Sociales/Estudio_Diag_Trabajo_2018.pdf [fecha de consulta: 5 de agosto de 2020].

Coneval (Consejo Nacional de Evaluación de la Política de Desarrollo Social) (2018c), Evaluación de la política de desarrollo social 2018, Ciudad de México, Coneval, disponible en: https://www.coneval.org.mx/Evaluacion/IEPSM/IEPSM/Paginas/IEPDS-2018. aspx [fecha de consulta: 5 de agosto de 2020].

Coneval (Consejo Nacional de Evaluación de la Política de Desarrollo Social) (2018d), Programas de cálculo y bases de datos 2008, 2010, 2012, 2014, 2016 y 2018, disponible en: https://www.coneval.org.mx/Medicion/MP/Paginas/Programas_BD_08_10_ 12_14_16_18.aspx [fecha de consulta: 5 de agosto de 2020].

Cunningham, W. (2009), "Unpacking Youth Unemployment in Latin America”, Policy Research Working Paper 5022.

Dávila, O. (2004), "Adolescencia y juventud", Ultima década, 21, Cidpa Valparaíso, Dor: https://doi.org/10.4067/S0718-22362004000200004.

De Oliveira, O. (2006), "Jóvenes y precariedad laboral en México”, Papeles de Población, 12(49), pp. 48-73.

(DOF) (Diario Oficial de la Federación) (1999), Ley del Instituto Mexicano de la Juventud (1999), Ciudad de México.

Duarte Quapper, K. (2012), “Sociedades adultocéntricas: Sobre sus orígenes y reproducción”, Ultima década, DoI: https://doi.org/10.4067/s0718-22362012000100005.

Feito, L. (2007), "Vulnerabilidad", Anales del Sistema Sanitario de Navarra, 30(3), pp. 7-22, DOI: https://doi.org/10.4321/S1137-66272007000600002.

GIRE (Grupo de Información en Reproducción Elegida) (2017), Violencia sin interrupción, Ciudad de México, GIRE, disponible en: https://aborto-por-violacion.gire.org.mx/\#/ [fecha de consulta: 5 de agosto de 2020].

Green, E.G.T., J.C. Deschamps y D. Páez (2005), "Variation of Individualism and Collectivism within and between 20 Countries: A Typological Analysis", Journal of Cross-Cultural Psychology, 36(3), pp. 321-339, Dor: https://doi.org/10.1177/0022022104273654.

Günther, I. y K. Harttgen (2009), "Estimating Households Vulnerability to Idiosyncratic and Covariate Shocks: A Novel Method Applied in Madagascar", World Development, 37(7), pp. 1222-1234, Dor: https://doi.org/10.1016/j.worlddev.2008.11.006.

Hofstede, G.H. (2001), Culture's Consequences: Comparing Values, Behaviors, Institutions and Organizations Across Nations, Thousand Oaks, Sage Publications, Dor: https://doi. org/10.1177/0022022110388567.

INEGI (Instituto Nacional de Estadística y Geografía) (1985-2020), Natalidad, Ciudad de México, INEGI, disponible en: https:/www.inegi.org.mx/sistemas/olap/proyectos/bd/ 
continuas/natalidad/nacimientos.asp?s=est\&c=23699\&proy=nat_nac [fecha de consulta: 5 de agosto de 2020].

INEGI (Instituto Nacional de Estadística y Geografía) (2014), Encuesta Nacional de Ingresos y Gastos de los Hogares (ENIGH), Ciudad de México, INEGI, disponible en: https:// www.inegi.org.mx/programas/enigh/nc/2014/ [fecha de consulta: 5 de agosto de 2020]. INEGI (Instituto Nacional de Estadística y Geografía) (2015), Encuesta Nacional de Inclusión Financiera (eNIF) 2015, Ciudad de México, INEGI, disponible en: https://www. inegi.org.mx/programas/enif/2015/ [fecha de consulta: 5 de agosto de 2020].

INEGI (Instituto Nacional de Estadística y Geografía) (2018), Encuesta Nacional de la

Dinámica Demográfica, Ciudad de México, INEGI, disponible en: https://www.inegi. org.mx/programas/enadid/2018/ [fecha de consulta: 5 de agosto de 2020].

INEGI (Instituto Nacional de Estadística y Geografía) (2019), Encuesta Nacional de Ocupación y Empleo, Ciudad de México, INEGI.

INEGI (Instituto Nacional de Estadística y Geografía) (2021), Encuesta Nacional de Ocupación y Empleo, Ciudad de México, INEGI, disponible en: https://www.inegi.org. $\mathrm{mx} /$ sistemas/olap/proyectos/bd/encuestas/hogares/enoe/2010_pe_ed15/pda.asp?s=est\& proy=enoe_pe_ed15_pda\&p=enoe_pe_ed 15 [fecha de consulta: 5 de agosto de 2020]. Kahn, L.B. (2010), "The Long-term Labor Market Consequences of Graduating from College in a Bad Economy”, Labour Economics, 17(2), pp. 303-316, Dor: https://doi. org/10.1016/j.labeco.2009.09.002.

Kleven, H., C. Landais y J.E. Søgaard (2018), "Children and Gender Inequality: Evidence from Denmark", documento de trabajo 01/18, Center for Economic Behavior and Inequality (CEBI), DOI: https://doi.org/10.2139/ssrn.3113273.

Laca, F., J. Mejía, E. Mayoral y C. Yánez (2012), "Violence Related Attitudes, Horizontal Individualism, and Collectivism in Young Mexicans", Psychology Journal, 9(1), pp. 2-12. Martínez Avińa, J.T. (2020), Una propuesta para reformar el sistema de pensiones en México, México, Conferencia Interamericana de Seguridad Social (cIss).

Medina-Mora, M.E., G. Borges, C. Lara Muñoz, C. Benjet, J. Blanco Jaimes, C. Fleiz Bautista, S. Aguilar-Gaxiola (2003), "Prevalencia de trastornos mentales y uso de servicios: Resultados de la Encuesta Nacional de Epidemiología Psiquiátrica en México", Salud Mental, 26(4).

Medina-Mora, M.E., G. Borges, C. Benjet, M. del C. Lara, E. Rojas, C. Fleiz, S. AguilarGaxiola (2009), "Estudio de los trastornos mentales en México: Resultados de la Encuesta Mundial de Salud Mental”, en J. Rodríguez, R. Kohn y S. Aguilar-Gaxiola (eds.), Epidemiologia de los trastornos mentales en América Latina y el Caribe, Washington, DC, Organización Panamericana de la Salud, pp. 79-89.

Moreno Crossley, J.C. (2008), "El concepto de vulnerabilidad social en el debate en torno 
a la desigualdad: Problemas, alcances y perspectivas", documento de trabajo 9, Observatory on Structures and Institutions of Inequality in Latin America, University of Miami-Center for Latin American Studies.

Morrow, V. (2013), “Troubling Transitions? Young People’s Experiences of Growing up in Poverty in Rural Andhra Pradesh, India”, Journal of Youth Studies, Dor: https://doi.org /10.1080/13676261.2012.704986.

Nájera Catalán, H.E. (2016), Youth Poverty and Social Inequalities in Mexico, Bristol, University of Bristol.

OCDE (Organización para la Cooperación y el Desarrollo Económicos) (2013), Resultados PISA 2012, OCDE.

OCDE (Organización para la Cooperación y el Desarrollo Económicos) (2016), PISA 2015: Nota Pais-Resultados PISA 2015, oCDE, disponible en: https://www.oecd.org/pisa/PISA2015-Mexico-ESP.pdf [fecha de consulta: 5 de agosto de 2020].

OIT (Organización Internacional del Trabajo) (2015), ¿Qué sabemos sobre los programas y politicas de Primer Empleo en América Latina? Lima, orт, Oficina Regional para América Latina y el Caribe, disponible en: https://www.ilo.org/wcmsp5/groups/public/--americas/---ro-lima/documents/publication/wcms_369021.pdf [fecha de consulta: 5 de agosto de 2020].

OІт (Organización Internacional del Trabajo) (2018), Reversing Pension Privatizations. Rebuilding public pension systems in Eastern Europe and Latin America, en I. Ortiz, F. DuránValverde, U. Stefan y V. Wodsak (eds.), Ginebra, Organización Internacional del Trabajo. Ramírez, B. (2019), "La necesaria construcción de un sistema público de pensiones para la sociedad mexicana”, El Trimestre Económico, https://doi.org/10.20430/ete.v86i344.982

Rodríguez Zepeda, J. (2014), "Prolegómenos de una teoría política de la igualdad de trato", en T. González Luna y J. Rodríguez Zepeda (eds.), Hacia una razón antidiscriminatoria: Estudios analíticos y normativos sobre la igualdad de trato, Ciudad de México, Conapred/ Rindis, pp. 31-71.

Rodríguez Zepeda, J. (2018), “Discriminación y pobreza: Cómo identificar la desventaja social”, en Pobreza y derechos sociales en México, Ciudad de México, Coneval/unam-IIS. sTps (Secretaría del Trabajo y Previsión Social) (s.f.), Jóvenes Construyendo el Futuro, Ciudad de México, sTPs, disponible en: https://jovenesconstruyendoelfuturo.stps.gob. $\mathrm{mx} /[$ fecha de consulta: 5 de agosto de 2020].

Szekely, M. e I. Flores (2018), "Educación y desarrollo en México: Una historia de baja capacidad de aprovechamiento del capital humano", documento de trabajo IDB-WP-933, Banco Interamericano de Desarrollo, Dor: https://doi.org/10.18235/0001428.

Téllez Infantes, A. (2013), "El análisis de la adolescencia desde la antropología y la perspectiva de género", Interaçôes, 25, pp. 52-73. 
Triandis, H.C. (2001), "Individualism-Collectivism and Personality", Journal of Personality, 69(6), pp. 907-924, DoI: https://doi.org/10.1111/1467-6494.696169.

Triandis, H.C., R. Bontempo, M.J. Villareal, M. Asai y N. Lucca (1988), “Individualism and Collectivism: Cross-cultural Perspectives on Self-ingroup Relationships”, Journal of Personality and Social Psychology, 54(2), pp. 323-338, Dor: https://doi.org/10.1037/ 0022-3514.54.2.323.

Unicef (Fondo de las Naciones Unidas para la Infancia) (2013), Superando el adultocentrismo, Santiago de Chile, Unicef.

Vandecasteele, L. (2015), "Social Class, Life Events and Poverty Risks in Comparative European Perspective", International Review of Social Research, 5, pp. 61-74, DoI: https:// doi.org/10.1515/irsr-2015-0005.

Walther, A. (2006), "Regimes of Youth Transitions”, Young, 14(2), pp. 119-139, DoI: https:// doi.org/10.1177/1103308806062737.

Weller, J. (2007), "La inserción laboral de los jóvenes: Características, tensiones y desafíos”, Revista de la CEPAL, 92, pp. 61-82.

Ana Heatley Tejada es investigadora en el Departamento de Estudios sobre Desigualdad Social y Poblaciones Vulnerables del Consejo Nacional de Evaluación de la Política de Desarrollo Social. Sus principales temas de investigación son el bienestar subjetivo, la pobreza y la desigualdad social. Se interesa en aplicar enfoques teóricos y metodológicos inter y transdisciplinarios al estudio de fenómenos sociales complejos. Es doctora en Psicología por la Universidad Nacional Autónoma de México, maestra en Antropología Psicológica por la London School of Economics y licenciada en Etnología por la Escuela Nacional de Antropología e Historia. Realizó una estancia de investigación en la Universidad de Oxford y actualmente es miembro del Sistema Nacional de Investigadores. 